\title{
EFFECTS OF ADRENERGIC BLOCKING AGENTS ON HUMAN FALLOPIAN TUBE MOTILITY IN VITRO
}

\author{
H. NAKANISHI AND CARL WOOD \\ Department of Obstetrics and Gynaecology, Monash University, \\ Queen Victoria Hospital, Melbourne, Australia
}

(Received 27th April 1967)

\begin{abstract}
Summary. An in-vitro perivascular nerve-muscle preparation of the human Fallopian tube was studied to assess the potency of various adrenergic blocking agents and beta-receptor stimulants. The administration of alpha-blocking agents, i.e. phenoxybenzamine, phentolamine, tolazoline, yohimbine and hydergine depressed and sometimes reversed the contractile response to nerve stimulation (sympathetic reversal) while the contractile response to noradrenaline was always changed to relaxation following treatment with these drugs. After pre-treatment with alpha-blocking drugs, the inhibitory responses to nerve stimulation and noradrenaline were strongly depressed or abolished by beta-blocking agents, i.e. propranolol and dichloroisoprenaline. Unexpectedly, the contractile response to nerve stimulation was gradually depressed when using the beta-blocking agent, propranolol, alone whereas the contraction in response to noradrenaline was augmented by this drug.

The administration of various beta-receptor stimulants always caused a decrease of muscle tone. The inhibitory activity increased in the following order: Du21220, adrenaline in the presence of phenoxybenzamine, isoprenaline and Cc-25. The inhibitory effect of the beta-stimulants was strongly depressed after pre-treatment with propranolol and dichloroisoprenaline. The blocking potency of propranolol was more marked than that of dichloroisoprenaline.

The isthmus region of the tube was more sensitive to autonomic agents and nerve stimulation than the ampulla. This suggests the isthmus acts as a sphincter.
\end{abstract}

\section{INTRODUCTION}

Investigators have speculated on the relationship between disorders of the isthmus of the Fallopian tube and infertility in a variety of mammals. Meaker (1924), Kroger (1962) and Stallworthy (1963) described a group of women having anatomically normal tubes, yet high or complete resistance to the passage of gas through them. The administration of an anti-spasmodic drug decreased the resistance indicating that it was due to functional tubal spasm (Meaker, 1924). Furthermore, Kennedy (1925) observed spasm of the isthmus of the tube in a certain number of sterile women with dysmenorrhoea. Recently, Brundin \& Wirsén (1964) used fluorescence microscopy to demonstrate that 
the circular muscle layer of the isthmus of the human tube is more abundantly supplied with adrenergic nerves than the ampulla and infundibulum. This dense adrenergic innervation of the tubal isthmus may be of aetiological significance in certain cases of infertility and ectopic pregnancy. The existence of cholinergic and adrenergic receptors in the human Fallopian tube has been shown by experiments carried out on in-vitro preparations by Sandberg, Ingelman-Sundberg, Lindgren \& Rydén (1960). In addition, Rosenblum \& Stein (1966) demonstrated the presence of alpha- and beta-adrenergic receptors in the circular muscle by measuring changes in the resting pressure of the perfused tubes in the response to autonomic drugs. In a previous study (Nakanishi, Wansbrough \& Wood, 1967) we showed that the longitudinal musculature of the human Fallopian tube was innervated predominantly by post-ganglionic sympathetic fibres, because the contractile response of the tissue to perivascular nerve stimulation was specifically depressed by pre-treatment with alpha-blocking agents, while the response was not affected by ganglionic or cholinergic blocking agents.

In the present study, we have investigated the effects of various adrenergic stimulating and blocking agents on the response of the human Fallopian tube to perivascular nerve stimulation.

\section{METHODS}

The Fallopian tube with its perivascular nerve was removed from thirty-five patients and prepared as described previously (Nakanishi et al., 1967): two of the patients were pregnant. Briefly, the preparation was suspended in Krebs' solution which was bubbled with $95 \%$ oxygen and $5 \%$ carbon dioxide, at $36^{\circ} \mathrm{C}$. The perivascular nerve was electrically stimulated with submaximal intensity, 30 pulses/sec frequency and $1 \mathrm{msec}$ pulse duration through the liquid electrode described by Garry \& Gillespie (1955), using an electrical stimulator (A.E.L. Model 104A stimulator). The nerve was usually stimulated for $10 \mathrm{sec}$ every 8 or $10 \mathrm{~min}$, except for the study of the effect of prolonged nerve stimulation $(1 \mathrm{~min})$. Isotonic longitudinal contractions were recorded on a running smoked drum.

The drugs used include: adrenaline tartrate, Cc-25 (1-(3,4-dihydroxyphenyl)-(4 hydroxyphenylisopropylamino) ethanol benzoate), dichloroisoprenaline hydrochloride, Du21220 (4-hydroxy- $\alpha$ (-1(2-(4-hydroxyphenyl)ethylamino) acetyl)-benzyl alcohol hydrochloride), hydergine (Sandoz Ltd), isoprenaline sulphate, noradrenaline bitartrate, phenoxybenzamine hydrochloride, phentolamine (Ciba Company Pty), propranolol hydrochloride, tolazoline (2-benzyl-4,5-imidazoline hydrochloride), and yohimbine hydrochloride. The final concentration of the drugs in the organ bath was expressed in $\mathrm{g} / \mathrm{ml}$.

\section{RESULTS}

\section{Effects of noradrenaline and nerve stimulation}

Noradrenaline in concentrations ranging from $2 \times 10^{-8}$ to $2 \times 10^{-6}$ caused contraction in twenty-eight out of thirty preparations. However, one prepara- 
tion which was taken from a 61-yr-old woman relaxed when noradrenaline, $2 \times 10^{-8}$ to $2 \times 10^{-6}$ was administered. Another preparation taken from a 70 -yr-old patient was unaffected by noradrenaline, ranging from $2 \times 10^{-7}$ to $2 \times 10^{-6}$.

Perivascular nerve stimulation always caused contraction of the Fallopian tube. The isthmus was more sensitive than the ampulla to both noradrenaline and nerve stimulation (Plate 1). In the two preparations from pregnant patients, the amplitude of response to noradrenaline $2 \times 10^{-6}$ and nerve stimulation was markedly less than that of the non-pregnant patients. In addition, no difference was found between the isthmic and ampullary region of the tube.

Effect of alpha-blocking agents on the contractile response to noradrenaline and nerve stimulation

The contraction in response to noradrenaline $\left(2 \times 10^{-6}\right)$ was strongly depressed or converted into relaxation in the presence of alpha-blocking agents, i.e. phenoxybenzamine $\left(2 \times 10^{-7}\right.$ to $\left.2 \times 10^{-5}\right)$, phentolamine $\left(2 \times 10^{-7}\right.$ to $\left.2 \times 10^{-5}\right)$, yohimbine $\left(2 \times 10^{-6}\right.$ to $\left.2 \times 10^{-5}\right)$, tolazoline $\left(2 \times 10^{-6}\right.$ to $\left.2 \times 10^{-5}\right)$ and hydergine $\left(2 \times 10^{-6}\right.$ to $\left.2 \times 10^{-5}\right)$ (Plate 2$)$.

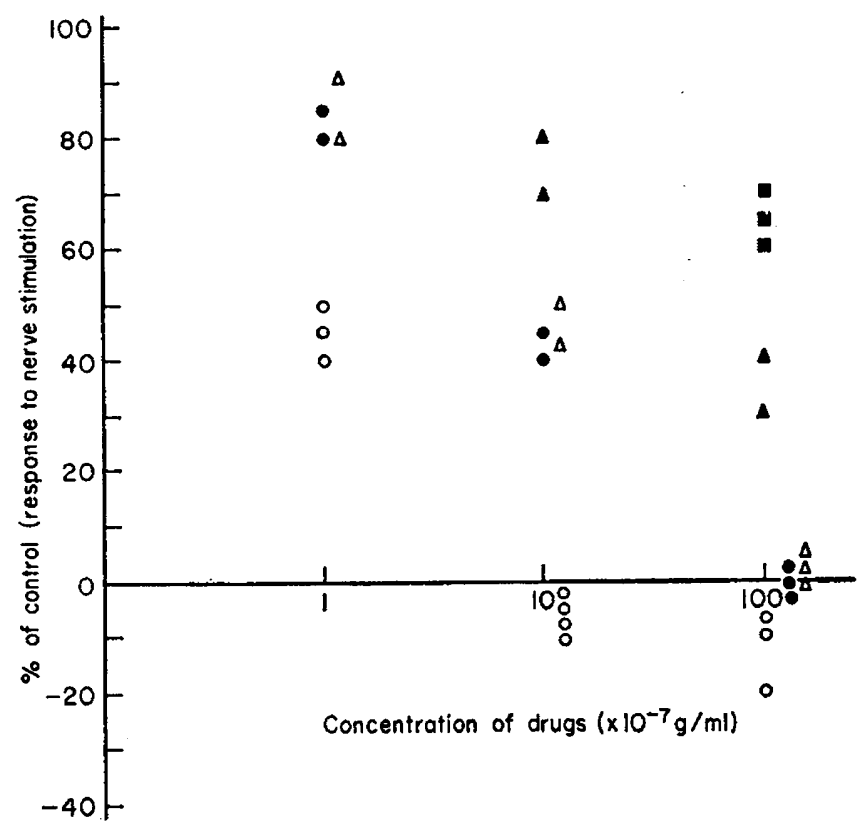

TEXT-FIG. 1. Effect of alpha-blocking agents $(O$, phenoxybenzamine; $\bullet$, phentolamine; $\Delta$, tolazoline; $\Delta$, yohimbine; $\square$, hydergine) on the contractile response of the human Fallopian tube to nerve stimulation. Note that phenoxybenzamine is the most effective blocking agent and hydergine the least. Abscissa is a logarithmic scale.

The contraction in response to nerve stimulation was also strongly depressed in the presence of alpha-blocking agents, i.e. phenoxybenzamine $\left(10^{-7}\right.$ to $\left.2 \times 10^{-5}\right)$, phentolamine $\left(10^{-7}\right.$ to $\left.2 \times 10^{-5}\right)$, yohimbine $\left(10^{-7}\right.$ to $\left.2 \times 10^{-5}\right)$, tolazoline $\left(2 \times 10^{-7}\right.$ to $\left.2 \times 10^{-5}\right)$ and hydergine $\left(1.2 \times 10^{-5}\right)$ (Plate 3$)$. 
In particular, in the presence of high doses of phenoxybenzamine (more than $\left.10^{-6}\right)$, the contractile response to nerve stimulation was changed to relaxation (sympathetic reversal), this effect usually being preceded by a small contractile response. Phenoxybenzamine was the most effective, hydergine the least and phentolamine, tolazoline and yohimbine were intermediate in their effect (Text-fig. 1). High doses of all the alpha-blocking agents increased the muscle tone.

Effects of beta-blocking agents on the contractile response to noradrenaline and nerve stimulation

The contraction in response to noradrenaline $\left(2 \times 10^{-6}\right)$ was unaffected by pre-treatment with a low dose of propranolol $\left(2 \times 10^{-8}\right)$. However, an

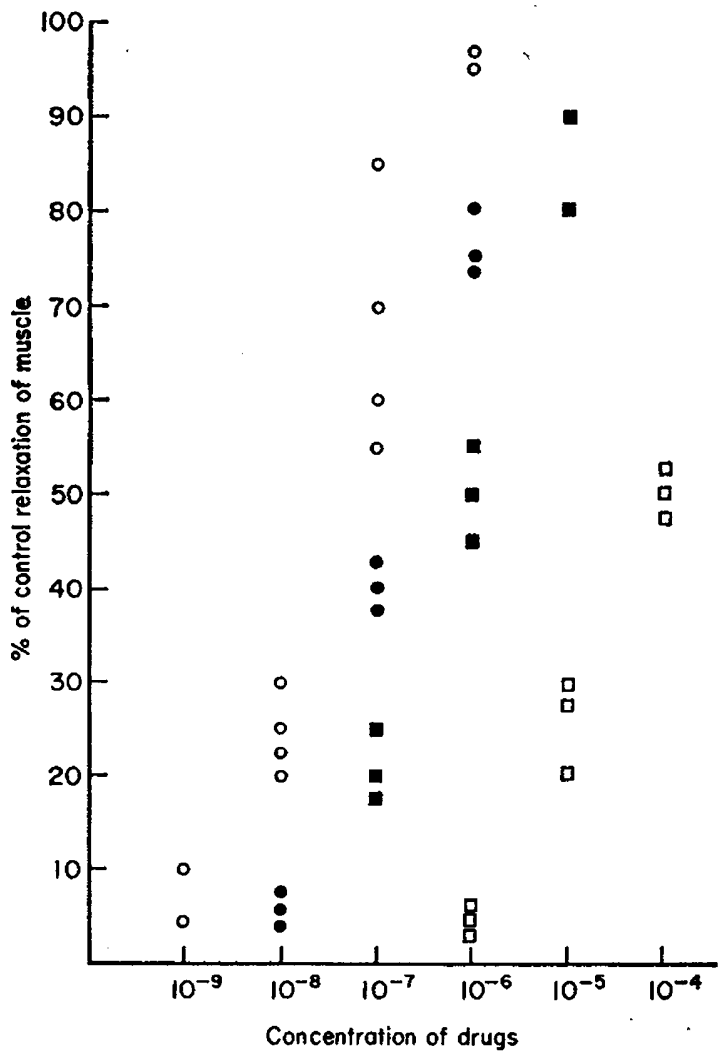

TEXT-FIG. 2. Effects of beta-stimulants ( $O$, Cc-25; $\square$, Du21220; $\bullet$, isoprenaline; adrenaline in the presence of phenoxybenzamine) on the muscle tone of human Fallopian tube. Cc-25 was the most effective relaxant and Du21220 was the least. Abscissa is a logarithmic scale.

increased dose $\left(10^{-7}\right.$ to $\left.2 \times 10^{-6}\right)$ of this drug caused slight augmentation of the contractile response to noradrenaline $\left(2 \times 10^{-6}\right)$. In contrast, the contraction in response to nerve stimulation was slightly depressed in the presence of 


\section{PLATE 1}

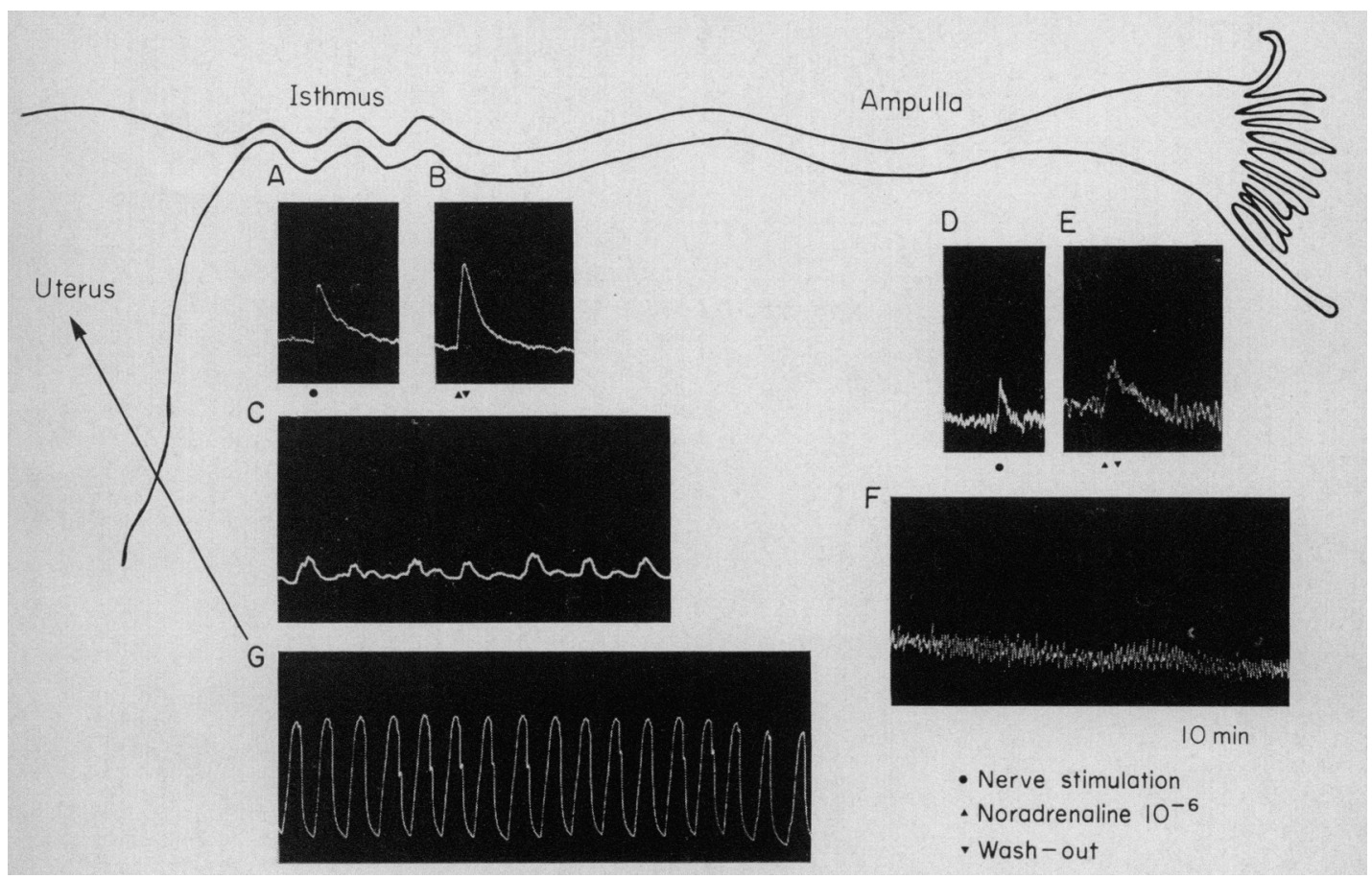

(A) Contractile response of isthmic region to perivascular nerve stimulation (30 pulses/ sec frequency, $1 \mathrm{msec}$ pulse width, submaximal intensity, $10 \mathrm{sec}$ duration).

(B) Contractile response of isthmic region to noradrenaline $\left(10^{-6}\right)$.

(C) Spontaneous movement of isthmic muscle.

(D) Contractile response of ampullary region to perivascular nerve stimulation (30 pulses/sec frequency, $1 \mathrm{msec}$ pulse width, submaximal intensity, 10 sec duration).

(E) Contractile response of ampullary region to noradrenaline $\left(10^{-6}\right)$.

(F) Spontaneous movement of ampullary muscle. Note the higher sensitivity of isthmic muscle to nerve stimulation and noradrenaline. The spontaneous contractions of the isthmus have a lower frequency and higher amplitude compared to the ampulla.

(G) Spontaneous movement of muscle from uterine body. 


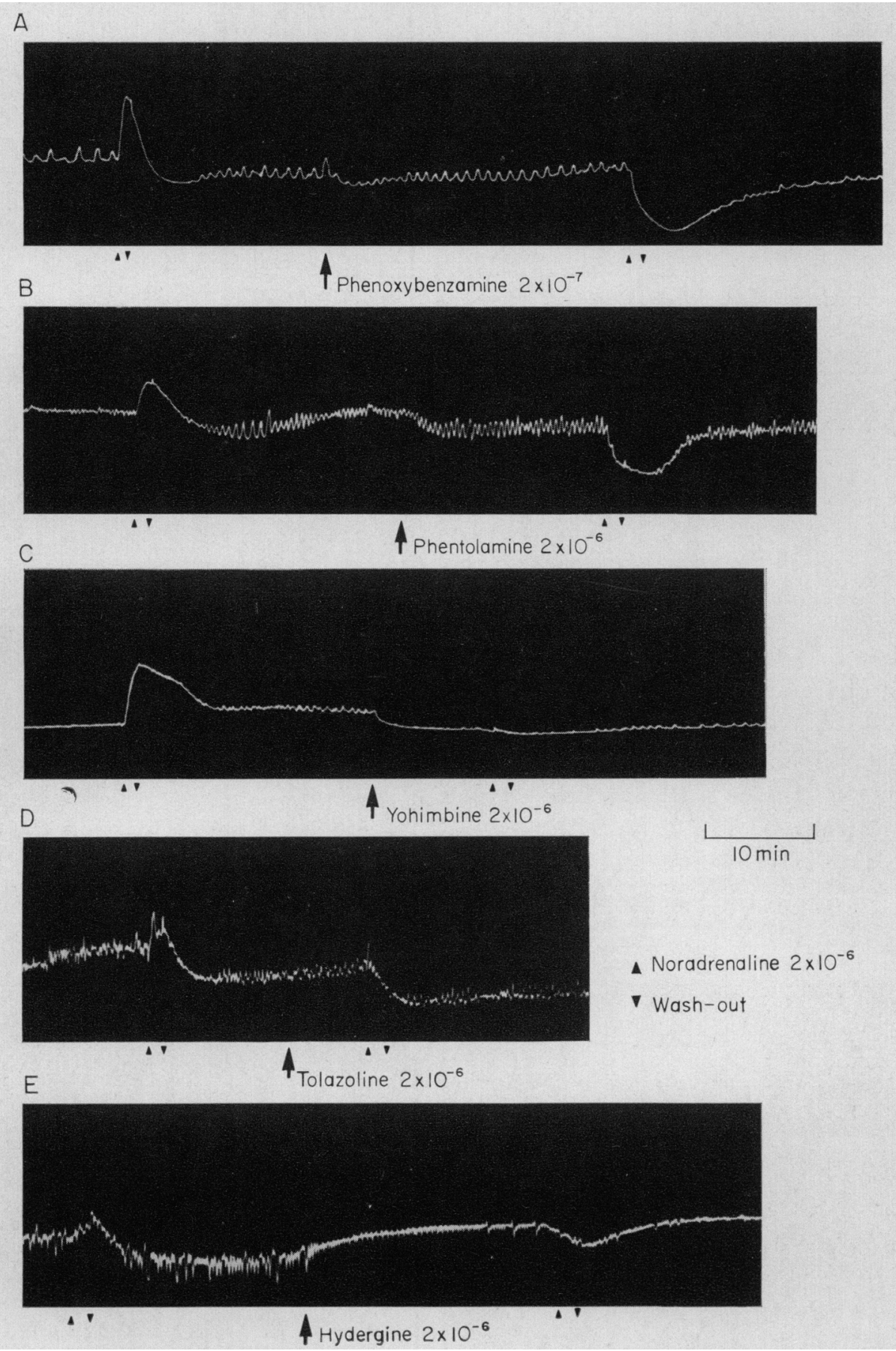

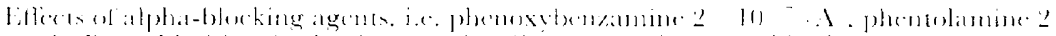

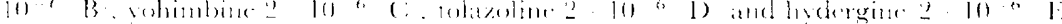

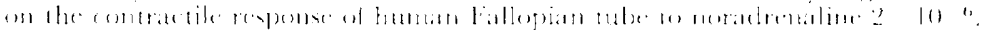



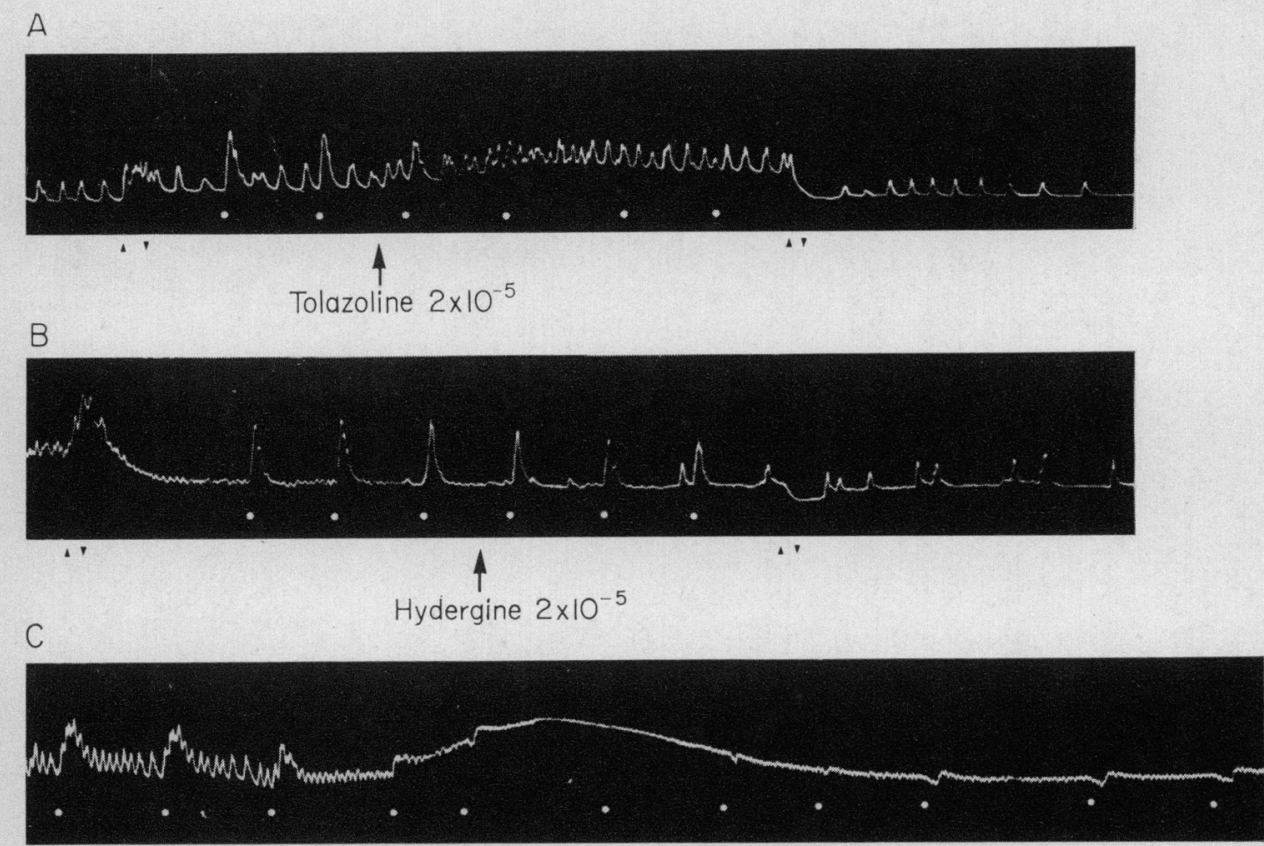
$\uparrow$

D Phenoxybenzamine $2 \times 10^{-6}$
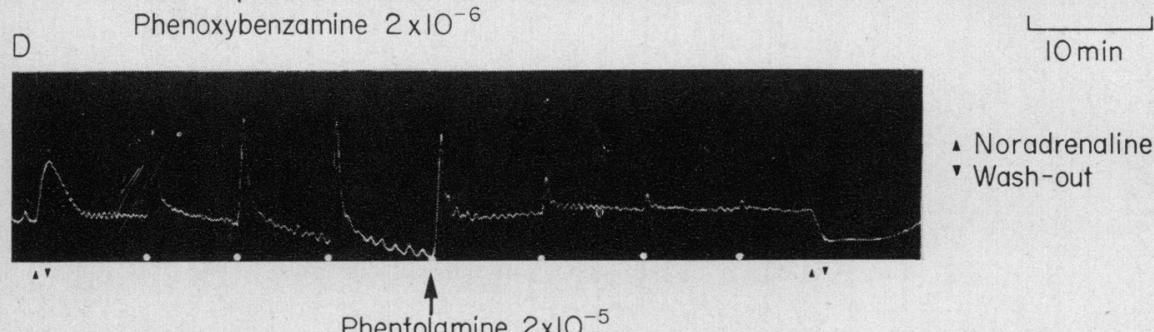

E

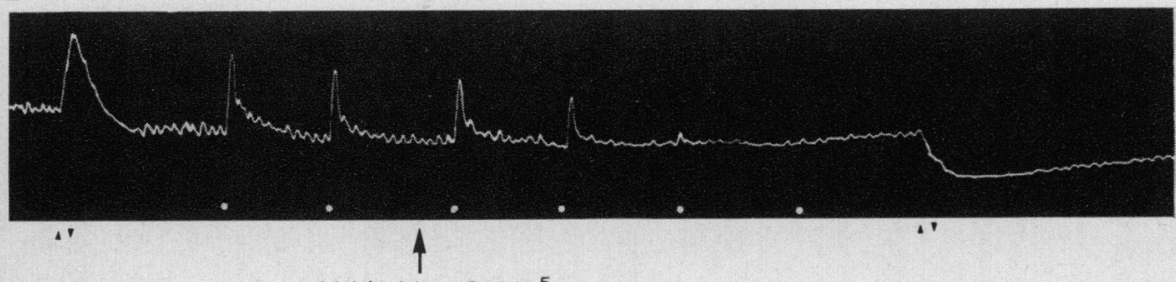

Yohimbine $2 \times 10^{-5}$

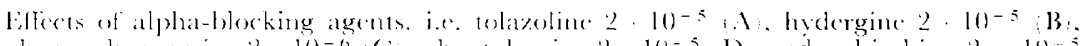

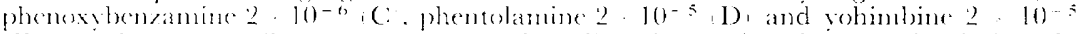
E. on the contratile response to moradrenaline $2 \cdot 10^{-6}$ and nerve stimulation 130

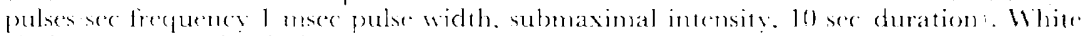
ircles = merrestimulation. 


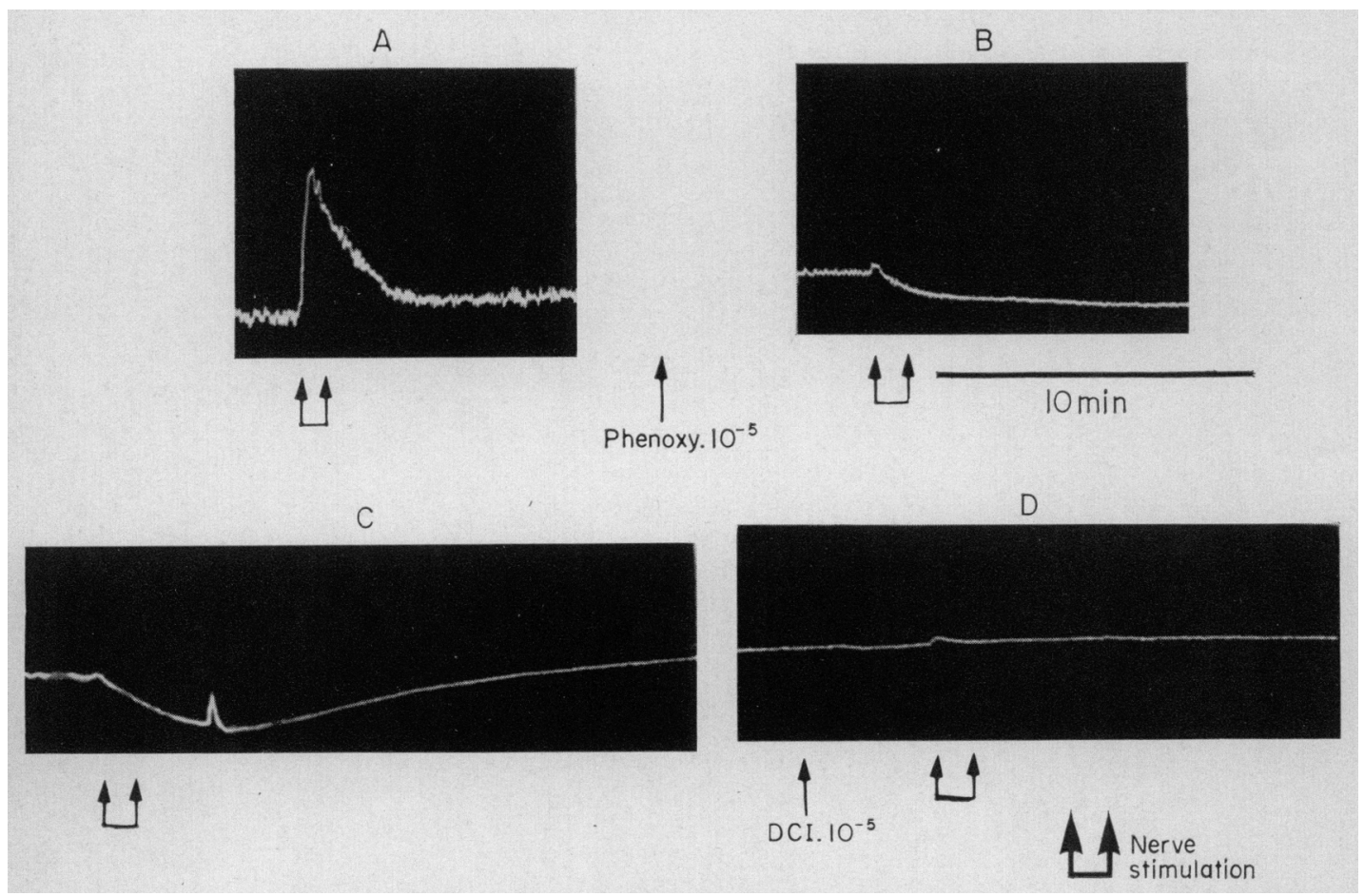

Effect of phenoxybenzamine and DCiI on the response to prolonged nerve stimulation (30 pulses/sec frecuency, $1 \mathrm{msec}$ pulse width, submaximal intensity, $1 \mathrm{~min}$ duration).

(A) Contraction in response to prolonged nerve stimulation.

(B) Relaxation in response to prolonged nerve stimulation in the presence of phenoxybenzamine $10^{-5}$

(C) Relaxation in response to prolonged nerve stimulation in the presence of phenoxybenzamine $10^{-5}$. The inhibition began to recover after washing the preparation.

(D) Relaxation after prolonged nerve stimulation in the presence of phenoxybenzamine $10^{-5}$ was blocked by DCI $10^{-5}$. 
more than $10^{-7}$ of propranolol. The contraction in response to nerve stimulation was usually not affected by pretreatment with dichloroisoprenaline $\left(2 \times 10^{-6}\right.$ to $\left.2 \times 10^{-5}\right)$, while the contraction in response to noradrenaline $\left(2 \times 10^{-6}\right)$ was slightly potentiated.

The inhibitory responses to noradrenaline and to nerve stimulation in the presence of alpha-blocking agents were strongly depressed or abolished by pretreatment with propranolol $\left(2 \times 10^{-6}\right.$ to $\left.10^{-5}\right)$ or dichloroisoprenaline $\left(10^{-5}\right)$.

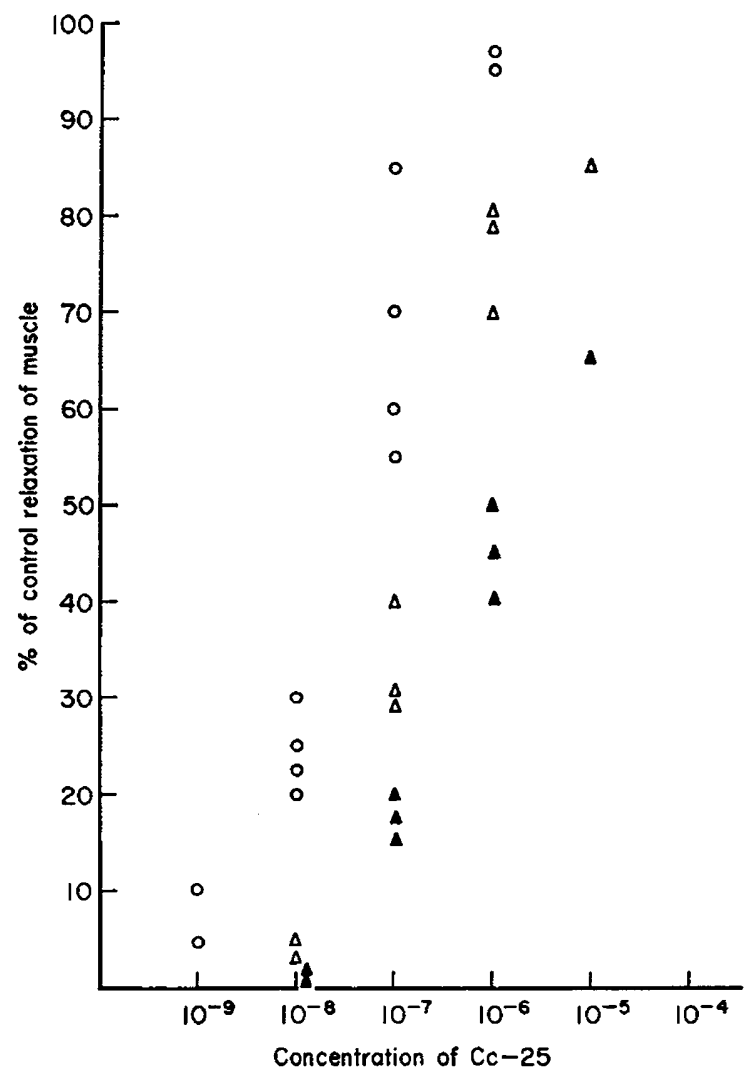

TEXT-FIG. 3. Effects of DGI $10^{-6}(\triangle)$ and propranolol $10^{-6}(\Lambda)$ on the relaxant effect of Cc-25. C, Control. In the presence of these beta-blocking agents the dose-response curve was displaced to the right.

Propranolol $\left(2 \times 10^{-6}\right)$ blocked the relaxant effect of noradrenaline on the Fallopian tube taken from the 61-year-old patient. Sometimes the inhibitory response to noradrenaline after various alpha-blocking agents was changed to slight excitation by these beta-blocking agents. Moreover, more prolonged stimulation ( $1 \mathrm{~min}$ ) was needed in order to obtain maximal inhibitory response. This response appeared after a latent period, and was sometimes preceded by a small contraction. When stimulation was stopped, the relaxation remained for a long time before the muscle started to recover. The inhibitory response to prolonged stimulation was also blocked by dichloroisoprenaline $\left(10^{-5}\right)$ (Plate 4$)$. 
Effects of adrenaline in the presence of phenoxybenzamine, isoprenaline, Cc-25 and Du21220 on spontaneous motility

The administration of these beta-stimulants, i.e. adrenaline $\left(10^{-8}\right.$ to $\left.10^{-5}\right)$ in the presence of phenoxybenzamine $\left(2 \times 10^{-6}\right)$, isoprenaline $\left(10^{-8}\right.$ to $\left.10^{-6}\right)$, Cc-25 $\left(10^{-9}\right.$ to $\left.10^{-6}\right)$ and Du21220 $\left(10^{-6}\right.$ to $\left.10^{-4}\right)$ caused a graded decrease of muscle tone, showing sigmoidal dose-response curves (Text-fig. 2). The relaxing effect of these drugs increased in the following order: Du21220, adrenaline in the presence of phenoxybenzamine, isoprenaline and Cc-25. The isthmus was more sensitive than the ampulla to beta-stimulants. The inhibitory response gradually disappeared after wash-out.

Effects of beta-blocking agents on the inhibitory effects of adrenaline in the presence of phenoxybenzamine, isoprenaline, $C_{c}-25$ and Du21220

The inhibitory effects of the beta-stimulants, i.e. adrenaline $\left(2 \times 10^{-6}\right)$ in the presence of phenoxybenzamine $\left(2 \times 10^{-6}\right)$, isoprenaline $\left(2 \times 10^{-7}\right.$ to $2 \times$ $\left.10^{-6}\right)$, Gc-25 $\left(10^{-8}\right.$ to $\left.10^{-5}\right)$ and Du21220 $\left(10^{-4}\right)$ were strongly blocked or abolished by pre-treatment with propranolol $\left(2 \times 10^{-6}\right.$ to $\left.10^{-5}\right)$ and dichloroisoprenaline $\left(2 \times 10^{-6}\right.$ to $\left.10^{-5}\right)$. The dose-response curves of Cc-25 and isoprenaline in the presence of these beta-blocking agents were displaced to the right but remained parallel (Text-fig. 3). The blocking activity of propranolol was stronger than that of dichloroisoprenaline. Partial recovery from the betablocking drugs was effected by repeated wash-out.

\section{DISCUSSION}

In spite of suggestions that autonomic innervation of the mammalian tube influences reproductive function, very few reports have been presented on this subject. The presence of cholinergic and adrenergic receptors in the human Fallopian tube has been demonstrated by studying its spontaneous contractility in vitro (Sandberg et al., 1960). In our previous pharmacological study of the human Fallopian tube the nerve supplying the muscle was shown to consist of predominantly post-ganglionic adrenergic fibres (Nakanishi et al., 1967). In both the rabbit and human, Brundin (1964) and Brundin \& Wirsén (1964) used a fluorescent histochemical technique to show that adrenergic nerve terminals supplying the muscle of the isthmic portion of the tubes were more abundant than those supplying the uterine myometrium. Furthermore, they also demonstrated that adrenergic nerve terminals were unevenly distributed along the Fallopian tube, being more concentrated in the isthmus.

The present experiments confirmed that stimulation of the nerve supplying the human Fallopian tube causes contractions and also that this nerve is adrenergic, as the contractile response was depressed by pre-treatment with alpha-blocking agents. One interesting finding was that the isthmus of the tube was more sensitive than the ampulla to nerve stimulation and autonomic drugs. This finding is consistent with the abundance of adrenergic nerve terminals found in the muscle layer of the isthmus by Brundin \& Wirsén (1964). The pharmacological and histochemical evidence of a rich innervation of the tubal 
isthmus suggests it may function as a sphincter in the manner of other mammalian sphincters innervated by adrenergic nerves (Hamberger \& Norberg, 1965). Constriction of the isthmus during menstruation would effectively prevent the retrograde flow of blood through the tube into the peritoneal cavity. On the other hand, constriction of the isthmus might cause functional tubal blockage. Uterotubal spasm has been demonstrated in patients when gas or radio-opaque dye will pass through the tubes on one occasion but not on others. In addition, constriction of the isthmus in the latter part of the menstrual cycle might prevent a fertilized ovum embedding at the point of entry of the tube into the uterine cavity.

The Fallopian tubes of two pregnant patients were less sensitive than those of the nonpregnant women to both nerve stimulation and noradrenaline. The addition of progesterone to oestrogen-primed rabbits has been shown to convert the uterine response to hypogastric nerve stimulation from excitation to inhibition (Miller \& Marshall, 1965) and it is possible that progesterone also may be responsible for the decreased response of the pregnant human Fallopian tube to nerve stimulation or noradrenaline. In contrast to the non-pregnant, the isthmus of the tubes from the two pregnant patients had no greater response to nerve stimulation and noradrenaline than the ampulla. These findings indicate that the isthmus could not act as a sphincter during pregnancy which would be consistent with our own hypothesis concerning its functional role only at the time of nidation and during menstruation.

Although the tubes of two post-menopausal patients reacted normally to acetylcholine, nerve stimulation produced only slight excitation and noradrenaline $\left(10^{-6}\right.$ to $\left.10^{-8}\right)$ inhibition. The poor response of these tubes to nerve excitation suggests the isthmus no longer acts as a sphincter, but in the absence of ovulation or menstruation this would not matter. The change in the response of the tube in post-menopausal patients may be associated with an increase of beta-receptors, a decrease of alpha-receptors or the withdrawal of endocrine influences on the tube.

Comparison of the potency of various alpha-blocking drugs showed that phenoxybenzamine was the most effective and hydergine the least, while tolazoline, phentolamine and yohimbine were intermediate in their effect. One unexpected finding was that the beta-blocking drug, propranolol, depressed the excitatory response to nerve stimulation while augmenting the effect of exogenous noradrenaline. The depression of the nerve-stimulated response may be due to the local anaesthetic action of propranolol whereby noradrenaline release from nerve terminals is prevented (Heim \& Hull, 1966). The interfering action of propranolol with adrenergic transmission may be one factor in its hypotensive action (Paterson \& Dollery, 1966).

The tube was very sensitive to beta-stimulants and their relaxant effect may be useful in the relief of tubal spasm. The most effective beta-mimetic drug was Cc-25, which also has marked inhibitory effects upon the human uterus, both in vivo (Stolte, Eskes, Seelen, Moed \& Vogelsang, 1965). The effects of betastimulants were blocked by both propranolol and dichloroisoprenaline, the former being more potent. 


\section{ACKNOWLEDGMENTS}

We wish to thank Mr J. F. Leeton and Dr W. A. W. Walters for their help in providing the material. We also wish to thank Mr H. G. Berkshire for his assistance with illustrations. The investigation was supported by the Australian University Commission and by the National Health and Medical Research Council of Australia.

\section{REFERENCES}

BRUNDIN, J. (1964) The distribution of noradrenaline and adrenaline in the fallopian tube of the rabbit. Acta physiol. scand. 62, 156.

BRUNDIN, J. \& WIRSÉn, C. (1964) Adrenergic nerve terminals in the human fallopian tube examined by fluorescence microscopy. Acta physiol. scand. 61, 505.

GaRRy, R. G. \& Gillespie, J. S. (1955) The response of musculature of the colon of the rabbit to stimulation, in vitro, of the parasympathetic and of the sympathetic outflows. F. Physiol., Lond. 128, 557 .

Hamberger, B. \& Norberg, K.-A. (1965) Adrenergic synaptic terminals and nerve cells in bladder ganglia of the cat. Int. F. Neuropharmac. 4, 41.

Heim, T. \& HulL, D. (1966) The effect of propranolol on the calorigenic response in brown adipose tissue of newborn rabbits to catecholamines, glucagon, corticotrophin and cold exposure. 7. Physiol., Lond. 187, 271.

KrnNedy, W. T. (1925) Isthmospasm of the fallopian tube. F. Am. med. Ass. 85, 13.

Kroger, W. S. (1962) Psychosomatic obstetrics, gynecology and endocrinology, Chap. 13, p. 339. Thomas, Springfield, Illinois.

MEAKER, S. R. (1924) The use in sterility of antispasmodic drugs. 7. Am. med. Ass. 82, 2089.

Millgr, M. D. \& Marshall, J. (1965) Uterine response to nerve stimulation; relation to humoral status and catecholamines. Am. F. Physiol. 209, 859.

Nakanishi, H., Wansbrovgh, H. \& Wood, C. (1967) Postganglionic sympathetic nerve innervating human fallopian tube. Am. F. Physiol. 213, 613.

Paterson, J. W. \& Dollery, C. T. (1966) Effect of propranolol in mild hypertension. Lancet, ii, 1148.

Rosenblum, I. \& Stein, A. A. (1966) Autonomic responses of the circular muscles of the isolated human fallopian tube. Am. F. Physiol. 210, 1129.

Sandberg, F., Ingelman-SundBerg, A., Lindgren, L. \& Rydén, G. (1960) In vitro studies of the motility of the human fallopian tube. Part I: The effect of acetylcholine, adrenaline, noradrenaline and oxytocin on the spontaneous motility. Acta obstet. gynec. scand. 39, 506.

Stallworthy, J. (1963) British obstetrics and gynaecological practice; gynaecology, 3rd edn, p. 711. Ed. A. Bourne. Heinemann, London.

Stolte, L., Eskes, T., Seelen, J., Moed, H. D. \& Vogelsang, C. (1965) Epinephrine derivates and the activity of the human uterus. I. The inhibitory effect of P-hydroxyphenyl isopropyl arterenol (Cc-25) upon uterine activity in human pregnancy. Am. F. Obstet. Gynec. 92, 865. 